\title{
Development of Low Cost Biogas Purification System
}

\author{
K. A. Sahu", S. R. Kalbande and V. P. Khambalkar \\ Department of Renewable Energy Sources, Dr.Panjabrao Deshmukh Krishi Vidyapeeth, \\ Akola (MS) 444104, India \\ *Corresponding author
}

A B S T R A C T

Ke y w o r d s
Biogas purification
system, $\mathrm{CO}_{2}$
scrubber, $\mathrm{H}_{2} \mathrm{~S}$
scrubber, Limestone
crystal, Iron
turnings
Article Info
Accepted:
07 March 2020
Available Online:
10 April 2020

Biogas is produced through anaerobic fermentation process of organic matter and it contains $\mathrm{CH}_{4}, \mathrm{CO}_{2}, \mathrm{H}_{2} \mathrm{~S}$ and other gases. The main combustible gas in biogas is $\mathrm{CH}_{4}$ and the presence of other gases reduces the calorific value of biogas, hence for obtaining better performance of engine it is essential to remove $\mathrm{CO}_{2}$ and $\mathrm{H}_{2} \mathrm{~S}$ present in raw biogas. The dry absorbent based biogas purification system was developed and its performance was evaluated. The major components of the biogas purification system include $\mathrm{CO}_{2}$ scrubber, $\mathrm{H}_{2} \mathrm{~S}$ scrubber, biogas analyzer, biogas flow-meter, biogas pump, pressure gauge, control valve and frame for holding the scrubber. The performance of the purification unit was evaluated for purification of biogas at bed heights of $15 \mathrm{~cm}, 20 \mathrm{~cm}$ and $25 \mathrm{~cm}$ with maintaining flow rates of $1.2 \mathrm{~m}^{3} / \mathrm{h}, 1.5 \mathrm{~m}^{3} / \mathrm{h}$ and $1.8 \mathrm{~m}^{3} / \mathrm{h}$. The purification unit was therefore observed to performed best at the optimum bed height of $20 \mathrm{~cm}$ and flow rate 1.5 $\mathrm{m}^{3} / \mathrm{h}$. The result of the study showed that the purification unit could purify the biogas satisfactorily. The payback period of the investment involved for the biogas purification unit was workout. The total cost of biogas purification system was Rs. 41000 with payback period of the investment of 3 years, 2 months and 13 days.

\section{Introduction}

Energy is an essential prerequisite for accelerated economic development and improved quality of life for citizens of any country. Due to rapid industrialization and urbanization in last few decades, there is a huge pressure on depletable crude oil, coal and other fossil fuels. This resulted into need for finding some alternative sources of energy. Biogas is one of the most important renewable sources of energy which may cope up to cater for heating and power. Biogas generated by the biological degradation of organic compound, has been considered as a valuable energy carrier, and it is now playing a key role in emerging market of renewable energy. Total biogas production in India is 2.07 billion $\mathrm{m}^{3} /$ year (Mittal et al., 2018).

Biogas is a clean renewable energy source for rural India. It mainly consists of methane (55-70\%), carbon dioxide (30-45\%), 
hydrogen sulphide $(<1 \%)$ and some traces of water vapour. Non-combustible constituent of biogas, carbon dioxide does not contribute to the combustion; in fact it lowers the heating value of biogas and increases the compression and transportation costs.

Hence there is an immense need of removal of carbon dioxide from biogas. Biogas production and subsequent purification will significantly satisfy the fuel requirement in rural as well as urban transport.

For using biogas as vehicle fuel, it has to be purified by removing the impurities like carbon dioxide, hydrogen sulphide and water vapour. These impurities can have detrimental effect on the life cycle and performance of the engine. Removal of carbon dioxide also enhances the calorific value.

Therefore, it is necessary to purify the biogas before using it for combustion. Biogas is a promising renewable fuel and produced by anaerobic digestion of biomass such as cattle dung, vegetable waste, municipal solid waste, poultry droppings, industrial waste water and landfill etc. Main products of the anaerobic digestion are biogas and slurry (Manjula and Mahanta, 2016).

Any low cost technique to remove carbon dioxide and hydrogen sulfide from biogas can make biogas a techno-commercially viable fuel (Shah et al., 2015).

\section{Materials and Methods}

\section{Location and site}

Akola is located at latitude $20.7^{\circ}$ north and longitude $77.07^{\circ}$ east. It is at an altitude of $287 \mathrm{~m}$ to $316 \mathrm{~m}$ above sea level. The experiment was conducted at the Department of Animal Husbandry and Dairy Science, Dr. PDKV Akola.

\section{Development of biogas purification system}

This system was mainly consisted of $\mathrm{CO}_{2}$ scrubber, $\mathrm{H}_{2} \mathrm{~S}$ scrubber, biogas analyzer, biogas flow meter, control valve, pressure gauge, biogas pump and frame for holding the scrubbers (Fig. 1-5 and Table 1-3).

\section{Sizing of biogas purification scrubber}

$\mathrm{H}_{2} \mathrm{~S}$ and $\mathrm{CO}_{2}$ scrubbers were used for purification of biogas. The size of scrubber was depended on adsorbents particle size. The size of scrubbers was calculated by following equations.

\section{Design procedure for $\mathrm{H}_{2} \mathrm{~S}$ and $\mathrm{CO}_{2}$ scrubber}

The $\mathrm{H}_{2} \mathrm{~S}$ scrubber was designed to remove the $\mathrm{H}_{2} \mathrm{~S}$ gas from biogas. In the design diameter of scrubber was taken as required and height of scrubber was calculated. The height and diameter of the scrubber was determined by using equation

\section{Cross section area of scrubber}

Area of section $=\frac{\text { Biogas per second in } \mathrm{cm}^{\mathrm{a}} / \mathrm{s}}{\text { Maximum flow rate in chamber in cm }}$
Radius of scrubber $=\sqrt{\frac{\text { Cross sectional area in square centimeter }}{\pi r^{2}}}$

Volume of scrubber

Volume of the scrubber $=\pi \mathrm{r}^{2}$

Where: $r$ - Radius of the scrubber, $\mathrm{cm}$

$\mathrm{h}$ - Height of the scrubber, $\mathrm{cm}$ 


\section{Height of the scrubber}

The height and cross sectional area of the chamber determine its volume. The volume determines the amount of absorbent that can be filled into the unit. The amount in turn determines the operating time of the chamber between absorbent exchanges.

$$
\text { Scrubber height }=\frac{\text { Chamber wolume in cubicmeter }}{\text { Cross section in Square meter }}
$$

Number of intermediate absorbent holding cylinder

The number of intermediate absorbent holding cylinder can be calculated as:

$$
\text { No. of cylinder }=\frac{\text { Height of chamber in meter }}{0.30 \mathrm{~m} \text { layer depth } / \text { Cylinder }}
$$

Sieve analysis of absorbents used for purification of biogas

The absorbent was used for the purification of biogas consist of limestone crystal, Iron turning, silica gel, etc. average particle size determined for the effective purification of biogas (Gaikwad, 2017).

Average particle size of the different absorbents was taken on the basis of fineness modulus.

\section{Fineness modulus}

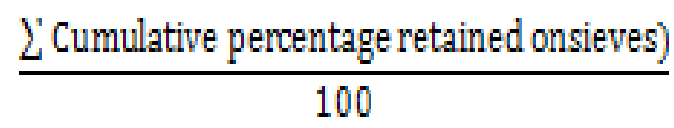

\section{Average particle size}

Where,

$$
\mathrm{D}_{\mathrm{avg}}=\frac{b}{\sqrt{a}} \times a^{F M}
$$

$a=$ constant (i.e. $a=2$ for India)

$\mathrm{b}=$ smallest sieve size in $\mathrm{mm}$.

\section{Economic feasibility of biogas purification system}

The economic feasibility of biogas purification system was calculated by using discount rate method. Following different economic indicators were used for economic analysis: Net present worth (NPW) Benefit cost ratio (B/C ratio) Payback period.

\section{Net present worth}

The mathematical statement for net present worth can be written as:

$$
\mathrm{NPW}=\sum_{t=1}^{t=n} \frac{B_{t}-C_{t}}{(1+i)^{t}}
$$

Where,

$\mathrm{C}_{\mathrm{t}}=$ Cost in each year

$\mathrm{B}_{\mathrm{t}}=$ Benefit in each year

$\mathrm{t}=1,2,3 \ldots \ldots \ldots \ldots \ldots . . \mathrm{n}$

$\mathrm{i}=$ discount rate

\section{Benefit cost ratio}

The mathematically benefit-cost ratio can be expressed as:

Benefit-cost ratio $=\sum_{t=1}^{\sum_{t=1}^{t=n} \frac{B_{t}}{(1+i)^{t}}} \frac{C_{t}}{(1+i)^{t}}$

Where,

$\mathrm{C}_{\mathrm{t}}=$ Cost in each year

$\mathrm{B}_{\mathrm{t}}=$ Benefit in each year

$\mathrm{t}=1,2,3$ ..n (year)

$\mathrm{i}=$ discount rate 
Table.1 Details of components of biogas purification system

\begin{tabular}{|c|c|c|}
\hline S.No. & Components & Details \\
\hline 1 & $\mathrm{CO}_{2}$ scrubber & $\begin{array}{l}\text { The } \mathrm{CO}_{2} \text { scrubber was made up of PVC pipe having height } 2400 \mathrm{~mm} \text {, and diameter } \\
152.4 \mathrm{~mm} \text {. The } \mathrm{CO}_{2} \text { scrubber consists of PVC pipe with end caps, to hold the } \\
\text { limestone crystals }\end{array}$ \\
\hline 2 & $\mathrm{H}_{2} \mathrm{~S}$ scrubber & $\begin{array}{l}\text { The } \mathrm{H}_{2} \mathrm{~S} \text { scrubber was made up of PVC pipe having height } 2400 \mathrm{~mm} \text {, and diameter } \\
152.4 \mathrm{~mm} \text {. The } \mathrm{H}_{2} \mathrm{~S} \text { scrubber consists of PVC pipe with end caps, to hold the iron } \\
\text { turnings }\end{array}$ \\
\hline 3 & Biogas analyzer & $\begin{array}{l}\text { The Biogas analyzer is an instrument which was used for analyzing the composition } \\
\text { of biogas. It analyzes the biogas and gives the concentrations of methane, carbon } \\
\text { dioxide and hydrogen sulphide in the biogas }\end{array}$ \\
\hline 4 & Biogas flow-meter & $\begin{array}{l}\text { The biogas flow meter measures the flow of biogas in cubic meter per hour. It was } \\
\text { attached to the system. The biogas flow was installed to measures the flow rate of } \\
\text { biogas at the inlet to the scrubber and also at the outlet of the scrubber. It also } \\
\text { checks the flow of biogas }\end{array}$ \\
\hline 5 & Biogas pump & $\begin{array}{l}\text { The biogas pump of } 0.5 \mathrm{hp} \text { was used to pump the biogas to the purification unit. } \\
\text { The biogas pump makes the flow of gas inside the purification unit with a pressure } \\
\text { which impacts the gas on the absorbents and helps in proper absorbtion }\end{array}$ \\
\hline 6 & Pressure gauge & $\begin{array}{l}\text { The pressure gauges were installed used to measure pressure of biogas at inlet and } \\
\text { the outlet of the biogas scrubbing unit. The pressure gauge help in regulating the } \\
\text { pressure of the gas thereby maintaining uniform flow of biogas inside the } \\
\text { purification unit for optimum absorbtion }\end{array}$ \\
\hline 7 & Control valve & $\begin{array}{l}\text { The control valve having size } 12.7 \mathrm{~mm} \text { was attached at the inlet and outlet of the } \\
\text { scrubbing unit. It was used to regulate the flow of biogas at the inlet and outlet. }\end{array}$ \\
\hline 8 & $\begin{array}{l}\text { Frame for holding } \\
\text { the scrubber }\end{array}$ & $\begin{array}{l}\text { The frame was made up of square mild steel pipe of } 25 \times 25 \mathrm{~mm} \text { size and thickness } \\
3 \mathrm{~mm} \text {. The frame holds the biogas scrubbing unit i.e. the PVC pipes, absorbents, } \\
\text { biogas pump, etc }\end{array}$ \\
\hline 9 & $\begin{array}{l}\text { Frame for holding } \\
\text { absorbent holding } \\
\text { cylinder }\end{array}$ & $\begin{array}{l}\text { A frame of } 300 \mathrm{~mm} \text { length was made up of M.S bars of } 8 \mathrm{~mm} \text { diameter and flat } \\
\text { spherical plates of } 150 \mathrm{~mm} \text {. The frame was developed for holdings the absorbents } \\
\text { holding cylinder inside it }\end{array}$ \\
\hline 10 & $\begin{array}{l}\text { Absorbent holding } \\
\text { cylinder }\end{array}$ & $\begin{array}{l}\text { The absorbents of diameter } 130 \mathrm{~mm} \text { and height } 300 \mathrm{~mm} \text { was fabricated of M.S } 1 \\
\text { mm wire mesh }\end{array}$ \\
\hline
\end{tabular}

Table.2 Absorbents used for biogas purification

\begin{tabular}{|l|l|l|l|}
\hline S.N. & \multicolumn{1}{|c|}{ Name of absorbent } & \multicolumn{1}{c|}{ Particle size } & \multicolumn{1}{c|}{ Function } \\
\hline $\mathbf{1}$ & Iron turning & $0.2-5 \mathrm{~mm}$ & To remove hydrogen sulphide gas \\
\hline $\mathbf{2}$ & Limestone crystal & $0.5-10 \mathrm{~mm}$ & To remove carbon dioxide \\
\hline $\mathbf{3}$ & Silica gel & $4-20 \mathrm{~mm}$ & To remove moisture \\
\hline
\end{tabular}

Table.3 Result obtained after examination

\begin{tabular}{|c|c|c|c|c|c|}
\hline \multicolumn{5}{|c|}{ Results obtained after experimentation } \\
\hline & Raw Biogas & \multicolumn{3}{c|}{ Purified Biogas } \\
\hline $\mathbf{C H}_{4}(\%)$ & $\mathrm{CO}_{2}(\%)$ & $\mathrm{H}_{2} \mathrm{~S}(\mathrm{ppm})$ & $\mathrm{CH}_{4}(\%)$ & $\mathrm{CO}_{2}(\%)$ & $\mathrm{H}_{2} \mathrm{~S}(\mathrm{ppm})$ \\
\hline $\mathbf{5 6 . 1 5}$ & 43.74 & 0.11 & 65.37 & 33.94 & 0.02 \\
\hline
\end{tabular}




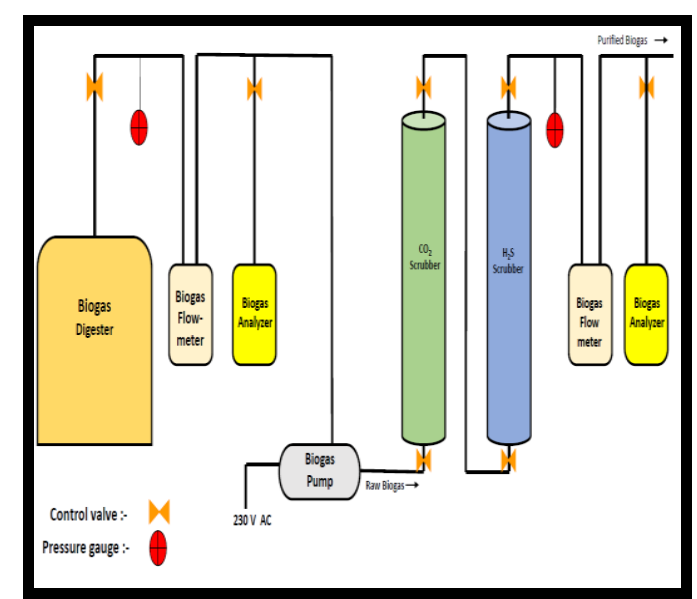

Fig.1 Experimental arrangement of biogas purification system

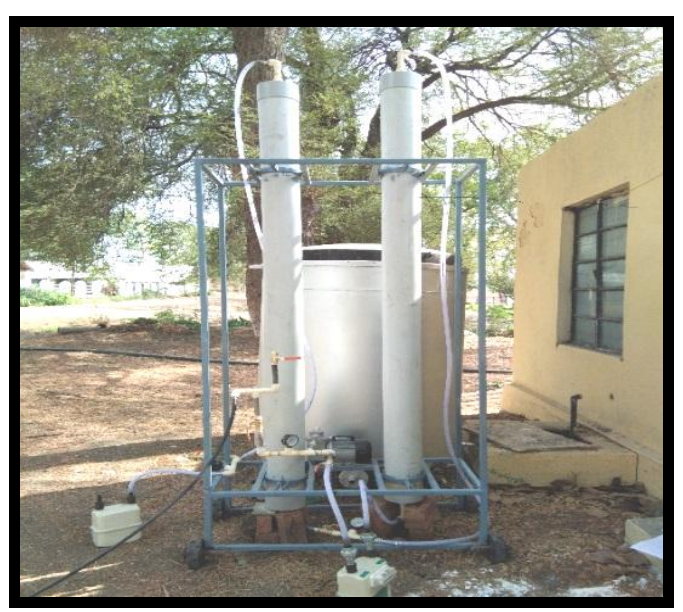

Fig.3 Developed Biogas purification unit

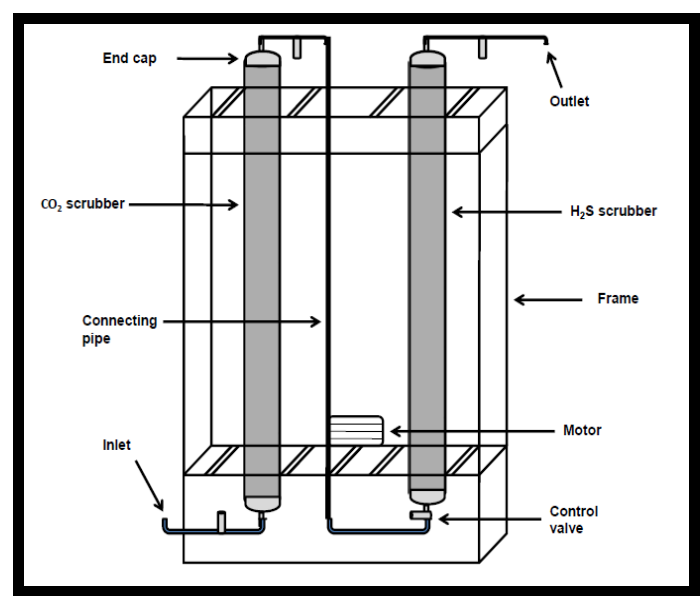

Fig.2 Schematic view of biogas purification system

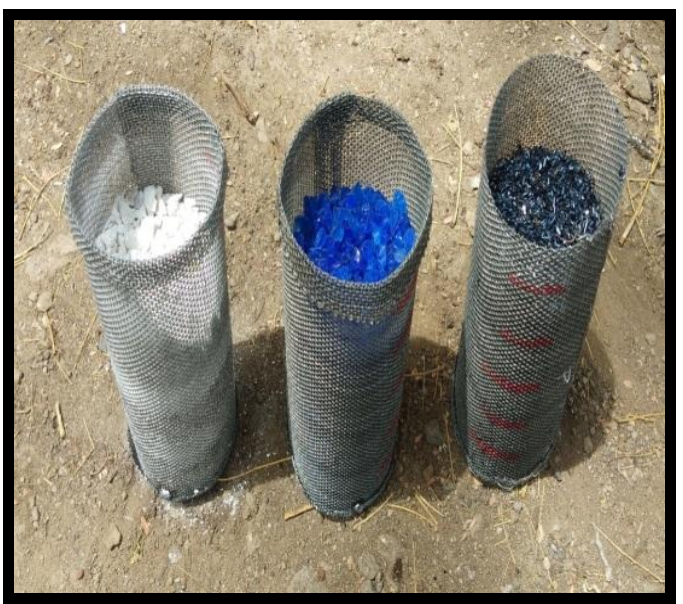

Fig.4 Absorbents used in biogas purification unit

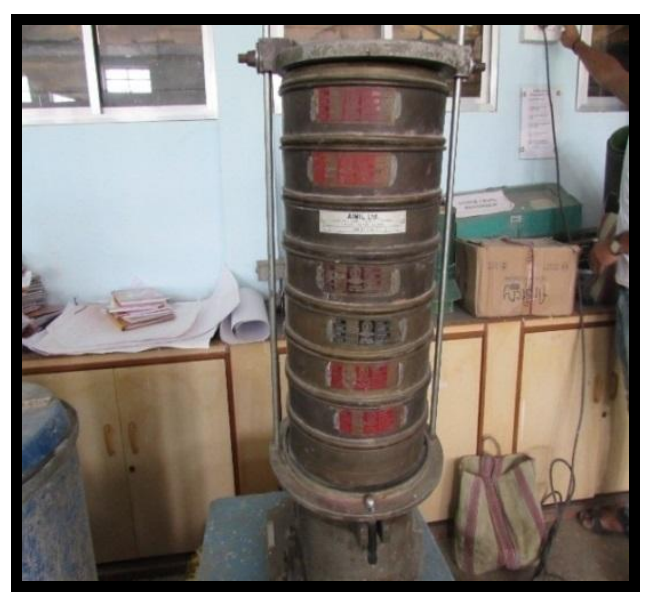

Fig.5 Sieve Analysis of absorbents

Fineness modulus 


\section{Payback period}

The mathematically payback period can be expressed as:

$$
\mathrm{P}=\frac{\mathrm{I}}{\mathrm{E}}
$$

Where,

$\mathrm{P}=$ Payback period of the project in years,

$\mathrm{I}=$ Investment of the project in rupees and

$\mathrm{E}=$ Annual net cash revenue in rupees

The performance of biogas purification system was found satisfactory at $20 \mathrm{~cm}$ bed height and $1.5 \mathrm{~m}^{3} / \mathrm{h}$ flow rate. The estimated cost of the system was Rs. 41000 with 12 year payback period and benefit cost ratio was found as 3 years 2 months and 13 days is 1.93. It could be inferred that the biogas purification system was economically feasible.

\section{References}

Gaikwad, V. R. and Katti P. K. 2014.Design of biogas scrubbing, compression \&storage system. J. of Electrical and Electronics Engineering. 2278: 58-63.
Kamble A. K. (2016). Modified biogas technology for the digestion of fresh undiluted cattle dung for energy generation. International Journal of Research in Engineering, Science and Technology. Vol 1, issue 9: 29-32.

Manjula, D. G. and Mahanta, P. 2016. Biogas purification using chemical absorption .In. J. of Engineering and Technology. 8(3): 0975-4024.

Mittal, S., Ahlgren, E. O. and Shukla, P. F. 2018. Barriers to biogas dissemination in India: A review 112:361-370.

Shah, D. and Hemant, N. 2015. Low cost biogas purification system for application of bio $\mathrm{CNG}$ as fuel for automobile engines. In. J. of Innovative Science, Engineering \& Technology. 2 (6): 308-312.

Vijay, V.K., Kapdi, S.S. 2006. Biogas purification and bottling into $\mathrm{CNG}$ cylinders producing BioCNG from biomass for Rural Automotive Applications. The second joint international conference on "Sustainable Energy and Environment "Bangkok, Thailand. Pp. 22-26.

\section{How to cite this article:}

Sahu. K. A., S. R. Kalbande and Khambalkar. V. P. 2020. Development of Low Cost Biogas Purification System. Int.J.Curr.Microbiol.App.Sci. 9(04): 791-796. doi: https://doi.org/10.20546/ijcmas.2020.904.094 